\title{
COINCIDENCE POINT THEOREMS FOR MULTIVALUED MAPPINGS
}

\author{
SHIH-SEN CHANG \\ Department of Mathematics \\ Sichuan University \\ Chengdu, Sichuan 610064 \\ People's Republic of China \\ YONG-CHENG PENG \\ Department of Mathematics \\ Shaoguan University \\ Shaoguan, Guangdong 512005 \\ People's Republic of China
}

(Received December 17, 1990 and in revised form March 2, 1991)

\begin{abstract}
Some new coincidence point and fixed point theorems for multivalued mappings in complete metric space are proved. The results presented in this paper enrich and extend the corresponding results in $[5-16,20-25,29]$.
\end{abstract}

KEY WORDS AND PHRASES: Multivalued mapping, coincidence point, and fixed point. 1991 AMS SUBJECT CLASSIFICATION CODES. 47H10, 54H25.

\section{INTRODUCTION AND PRELIMINARIES.}

In recent years, the existence and uniqueness of coincidence points and fixed points for commuting mappings, weakly commuting mappings and compatible mappings have been considered by several authors (see $[2,3,6,8,17-28])$. The purpose of this paper is to study the existence of coincidence points and fixed point for multivalued mappings in complete metric space from different aspects. The results presented in this paper enrich and extend the corresponding results in [5-16, 20-25, 29]. .

Throughout this paper, let $R^{+}-[0,+\infty)$ and $(X, d)$ a complete metric space. For any nonempty subsets $A$ and $B$ of $X$, we denote

$$
\begin{aligned}
& d(x, A)=\inf \{d(x, a): a \in A\}(x \in X), \\
& d(A, B)=\inf \{d(a, b): a \in A, b \in B\}, \\
& H(A, B)=\max \left\{\sup _{a \in A} d(a, b), \sup _{b \in B} d(b, A)\right\}, \\
& C C(X)=\{A: A \text { is a nonempty compact subset of } X\}, \\
& C B(X)=\{A: A \text { is a nonempty closed and bounded subset of } X\} .
\end{aligned}
$$

and $H(\cdot, \cdot)$ is called the Hausdorff metric on $C B(X)$. 
LEMMA 1 [4, Lemma 2.2]. Let $(X, d)$ be a metric space, $A \subset X$ a nonempty compact subset and $B \subset X$ a closed subset. If $d(A, B)=0$, then $A \cap B \neq \varnothing$.

REMARK 1. Even if $A$ and $B$ are both bounded closed subsets, the conclusion of Lemma 1 need not hold. This can be seen from the following

EXAMPLE 1. Let $X=R^{2}$ and $d$ the Euclidean metric on $R^{2}$. Letting

$$
\rho(\cdot, \cdot)=\min \{1, d(\cdot, \cdot)\},
$$

it is easy to verify that $\rho(\cdot, \cdot)$ is a metric on $R^{2}$. Therefore $\left(R^{2}, \rho\right)$ is also a metric space, and it is bounded. Now we consider the following subsets of $\left(R^{2}, \rho\right)$ :

$$
\begin{aligned}
& A=\left\{(x, y) \in R^{2}: y=\frac{1}{x}, x \geq \frac{1}{2}\right\} \\
& B=\left\{(x, y) \in R^{2}: y=0\right\}
\end{aligned}
$$

Then $A$ and $B$ are both bounded and closed and $d(A, B)=0$, but $A \cap B=\varnothing$.

LEMMA 2 [5, Theorem 1]. Let $\Phi: R^{+} \rightarrow R^{+}$be an increasing function such that

$$
\Phi(t+)<t \text { for all } t>0
$$

and

$$
\sum \Phi^{n}(t) \text { is finite for all } t>0 .
$$

Then there exists a strictly increasing function $\phi: R^{+} \rightarrow R^{+}$such that

$$
\Phi(t)<\phi(t) \text { for all } t>0
$$

and

$$
\sum \phi^{n}(t) \text { is finite for } t>0 .
$$

LEMMA 3 [5]. (i) If $\Phi: R^{+} \rightarrow R^{+}$is strictly increasing and satisfies (1.2), then $\Phi$ satisfies (1.1).

(ii) Let $\Phi: R^{+} \rightarrow R^{+}$be increasing and satisfies (1.1). If $\Sigma \Phi^{n}\left(t_{1}\right)$ is convergent for some $t_{1}>0$. Then (1.2) holds.

(iii) Let $\Phi: R^{+} \rightarrow R^{+}$be increasing and satisfies (1.1). If $t \leq \Phi(t)$ then $t=0$.

\section{MAIN RESULTS}

Recently, Kaneko and Sessa [6] extended the definition of compatibility to include multivalued mappings and proved the following theorem:

THEOREM 1. Let $f: X \rightarrow X$ and $T: X \rightarrow C B(X)$ be compatible continuous mapping such that $T(X) \subset f(X)$ and

$$
H(T x, T y) \leq \max \left\{d(f x, f y), d(f x, T x), d(f y, T y), \frac{1}{2}(d(f x, T y)+d(f y, T x))\right\}
$$

for all $x, y$ in $X$, where $0 \leq h<1$. Then there exists a point $x_{*} \in X$ such that $f x_{*} \in T x_{*}$.

As an improvement and generalization of Theorem 1, we have the following

THEOREM 2. Let $F: X \rightarrow C C(X), S, T: X \rightarrow C B(X)$ be three multivalued mappings such that $S(X) \cup T(X) \subset F(X), F(X)$ is closed and

$$
H(S x, T y) \leq \Phi\left(\max \left\{d(F x, F y), d(F x, S x), d(F y, T y), \frac{1}{2}(d(F x, T y)+d(F y, S x))\right\}\right)
$$


for all $x, y$ in $X$, where $\Phi: R^{+} \rightarrow R^{+}$is an increasing function satisfying conditions (1.1) and (1.2). Then there exists a point $z \in X$ such that

$$
F z \cap S z \cap T z \neq \varnothing .
$$

PROOF. By Lemma 2, there exists a strictly increasing function $\phi: R^{+} \rightarrow R^{+}$satisfying conditions (1.3) and (1.4). For any $x, y$ in $X$ let us denote

$$
A(x, y)=\max \left\{d(F x, F y), d(F x, S x), d(F y, T y), \frac{1}{2}(d(F x, T y)+d(F y, S x))\right\} .
$$

Then (2.1) can be reduced as follows:

$$
H(S x, T y) \leq \Phi(A(x, y)) .
$$

For any $x_{0} \in X$, since $S(X) \subset F(X)$, there exists an $x_{1} \in X$ such that $T x_{1} \cap S x_{0}=\varnothing$. Let $y_{1} \in F x_{1} \cap S x_{0}$, then we have

$$
\begin{aligned}
d\left(y_{1}, T x_{1}\right) & \leq H\left(S x_{0}, T x_{1}\right)\left(\text { since } y_{1} \in S x_{0}\right) \\
& \leq \Phi\left(A\left(x_{0}, x_{1}\right)\right)
\end{aligned}
$$

(a) If $A\left(x_{0}, x_{1}\right)=0$, then $d\left(F x_{0}, S x_{0}\right)=0$. By Lemma $1, F x_{0} \cap S x_{0} \neq \varnothing$. Taking $z \in F x_{0} \cap S x_{0}$, then we have

$$
\begin{aligned}
H\left(z, T x_{0}\right) & \leq H\left(S x_{0}, T x_{0}\right) \leq \Phi\left(A\left(x_{0}, x_{0}\right)\right) \\
& \leq \Phi\left(\max \left\{0,0, d\left(z, T x_{0}\right), \frac{1}{2} d\left(z, T x_{0}\right)\right\}\right) \\
& \leq \Phi\left(d\left(z, T x_{0}\right)\right) .
\end{aligned}
$$

By Lemma 3 (iii) $d\left(z, T x_{0}\right)=0$. Since $T x_{0}$ is closed, $z \in T x_{0}$. Therefore in this case the conclusion of Theorem 2 is proved.

(b) If $A\left(x_{0}, x_{1}\right)>0$, then, by (1.3) we have

$$
d\left(y_{1}, T x_{1}\right) \leq \Phi\left(A\left(x_{00}, x_{1}\right)\right)<\phi\left(A\left(x_{0}, x_{1}\right)\right)
$$

Consequently, we can find an $y_{2} \in T x_{1}$ such that

$$
d\left(y_{1}, y_{2}\right) \leq \phi\left(A\left(x_{0}, x_{1}\right)\right) \text {. }
$$

Since $T(X) \subset F(X)$, for $y_{2} \in T x_{1} \subset F(X)$, there exists a point $x_{2} \in X$ such that $y_{2} \in F x_{2}$. This implies that we can find an $y_{2} \in F x_{2} \cap T x_{1}$ such that (2.2) holds.

On the other hand, by the assumption we have

$$
d\left(S x_{2}, y_{2}\right) \leq H\left(S x_{2}, T x_{1}\right) \leq \Phi\left(A\left(x_{2}, x_{1}\right)\right) .
$$

If $A\left(x_{2}, x_{1}\right)=0$, by the same way as stated in the proof of (a) we can prove that the conclusion of Theorem 2 is true. If $A\left(x_{2}, x_{2}\right)>0$, repeating the same way mentioned above, we can find an $x_{3} \in X$ and $y_{3} \in F x_{3} \cap S x_{2}$ such that

$$
d\left(y_{3}, y_{2}\right) \leq \phi\left(A\left(x_{2}, x_{1}\right)\right) \text {. }
$$

Inductively, we can define two sequence $\left\{x_{n}\right\},\left\{y_{n}\right\} \subset X$ such that

$$
\left\{\begin{array}{l}
y_{2 n+1} \in F x_{2 n+1} \cap S x_{2 n} \\
y_{2 n+2} \in F x_{2 n+2} \cap T x_{2 n+1}
\end{array} \quad n=0,1,2, \ldots\right.
$$


and

$$
\left\{\begin{array}{l}
d\left(y_{2 n+1}, y_{2 n+2}\right) \leq \phi\left(A\left(x_{2 n}, x_{2 n+1}\right)\right) \\
d\left(y_{2 n+3}, y_{2 n+2}\right) \leq \phi\left(A\left(x_{2 n+2}, x_{2 n+1}\right)\right)
\end{array} \quad n=0,1,2, \ldots\right.
$$

Now we prove that $\left\{y_{n}\right\}$ is a Cauchy sequence in $X$. In fact, for any positive integer $n$ we have

$$
\begin{aligned}
A\left(x_{2 n}, x_{2 n+1}\right)= & \max \left\{d\left(F x_{2 n}, F x_{2 n+1}\right), d\left(F x_{2 n}, S x_{2 n}\right), d\left(F x_{2 n+1}, T x_{2 n+1}\right),\right. \\
& \left.\frac{1}{2}\left(d\left(F x_{2 n}, T x_{2 n+1}\right)+d\left(F x_{2 n+1}, S x_{2 n}\right)\right)\right\} \\
\leq & \max \left\{d\left(y_{2 n}, y_{2 n+1}\right), d\left(y_{2 n}, y_{2 n+1}\right), d\left(y_{2 n+1}, y_{2 n+2}\right),\right. \\
& \left.\frac{1}{2}\left(d\left(y_{2 n}, y_{2 n+2}\right)+d\left(y_{2 n+1}, y_{2 n+1}\right)\right)\right\} \\
\leq & \max \left\{d\left(y_{2 n}, y_{2 n+1}, d\left(y_{2 n+1}, y_{2 n+2}\right)\right\} .\right.
\end{aligned}
$$

By the same way we can prove that

$$
A\left(x_{2 n+2}, x_{2 n+1}\right) \leq \max \left\{d\left(y_{2 n+1}, y_{2 n+2}\right), d\left(y_{2 n+2}, y_{2 n+3}\right)\right\}
$$

Consequently, in general, we have

$$
\begin{aligned}
d\left(y_{n+1}, y_{n+2}\right) & \left.\leq \phi(A)\left(x_{n}, x_{n+1}\right)\right) \\
& \leq \phi\left(\max \left\{d\left(y_{n}, y_{n+1}\right), d\left(y_{n+1}, y_{n+2}\right)\right\}\right), \quad n=1,2, \ldots
\end{aligned}
$$

If $d\left(y_{n+1}, y_{n+2}\right)>d\left(y_{n}, y_{n+1}\right) \geq 0$, then, by (2.5) and Lemma 3 we have

$$
d\left(y_{n+1}, y_{n+2}\right) \leq \phi\left(d\left(y_{n+1}, y_{n+2}\right)\right)<d\left(y_{n+1}, y_{n+2}\right)
$$

a contradiction. Therefore we have $d\left(y_{n+1}, y_{n+2}\right) \leq d\left(y_{n}, y_{n+1}\right)$. Hence we have

$$
\begin{aligned}
d\left(y_{n}, y_{n+1}\right) & \leq \phi\left(d\left(y_{n-1}, y_{n}\right)\right) \leq \ldots \\
& \left.\leq \phi^{n-1} d\left(y_{1}, y_{2}\right)\right), \quad n=1,2, \ldots
\end{aligned}
$$

If $d\left(y_{1}, y_{2}\right)=0$, i.e. $y_{1}=y_{2}$, denoting $z=y_{1}=y_{2}$, then $z=y_{1} \in F x_{1} \cap S x_{0}, z=y_{2} \in F x_{2} \cap T x_{1}$. Hence $z \in F x_{1} \cap T x_{1}$. Similarly using the proof in (a) we can prove $z \in S x_{1}$. Hence the conclusion of Theorem 2 is proved.

If $d\left(y_{1}, y_{2}\right)>0$, in view of condition (1.4), we know that $\left.\Sigma \phi^{n-1} d\left(y_{1}, y_{2}\right)\right)$ is convergent. It follows from (2.6) that $\Sigma d\left(y_{n}, y_{n+1}\right)$ is convergent too. This implies that $\left\{y_{n}\right\}$ is a Cauchy sequence in $X$. Let it converge to some point $y_{*}$ in $X$. Since $y_{n} \in F x_{n} \subset F(X)$ and $F(X)$ is closed, this shows that $y_{*} \in F(X)$. Hence there exists $z \in X$ such that $y_{*} \in F z$. By (2.1) and (2.3) we have

$$
\begin{aligned}
d\left(y_{*}, S z\right) \leq d\left(y_{*},\right. & \left.y_{2 n+2}\right)+d\left(y_{2 n+2}, S z\right) \\
\leq & d\left(y_{*}, y_{2 n+2}\right)+H\left(T x_{2 n+1}, S z\right) \quad\left(\text { since } y_{2 n+2} \in T x_{2 n+1}\right) \\
\leq & d\left(y_{*}, y_{2 n+2}\right)+\Phi\left(A\left(z, x_{2 n+1}\right)\right) \\
\leq & d\left(y_{*}, y_{2 n+2}\right)+\Phi\left(\operatorname { m a x } \left\{d\left(F z, F x_{2 n+1}\right), d(F z, S z),\right.\right. \\
d\left(F x_{2 n+1}, T x_{2 n+1}\right), & \left.\left.\frac{1}{2}\left(d\left(F z, T x_{2 n+1}\right)+d\left(F x_{2 n+1}, S z\right)\right)\right\}\right) \\
\leq & d\left(y_{*}, y_{2 n+2}\right)+\Phi\left(\operatorname { m a x } \left\{d \left(d\left(y_{*}, y_{2 n+1}\right), d\left(y_{*}, S z\right),\right.\right.\right. \\
& \left.\left.d\left(y_{2 n+1}, y_{2 n+2}\right), \frac{1}{2}\left(d\left(y_{*}, y_{2 n+2}\right)+d\left(y_{2 n+1}, S z\right)\right)\right\}\right) .
\end{aligned}
$$

Letting $n \rightarrow \infty$, we have 


$$
\left.d\left(y_{\bullet}, S z\right) \leq \Phi \max \left\{0, d\left(y_{\bullet}, S z\right), 0, \frac{1}{2} d\left(y_{\bullet}, S z\right)\right\} \leq \Phi d\left(y_{\bullet}, S z\right)\right) \text {. }
$$

By Lemma 3 (iii) we have $d\left(y_{\bullet}, S z\right)=0$. Since $S z$ is closed, so that $y_{\bullet} \in S z$.

Similarly, we can prove that $y_{\bullet} \in T z$. Therefore we have $y_{\bullet} \in F z \cap S z \cap T z$.

This completes the proof.

REMARK 2. (i) Theorem 1 is a special case of Theorem 2 with $F$ being a single-valued mapping, $S=T$ and $\Phi(t)=h \cdot t$, where $0 \leq h<1$ and $t \in R^{+}$.

(ii) Even if the mapping $F$ in Theorem 2 is assumed to satisfy the condition " $F(X)$ is closed", Theorem 2 still weakens the continuity and compatibility conditions on $T$ in Theorem 1 . This can be seen from the following Example:

EXAMPLE 2. Let $X=R^{+}$and $f$ and $g$ be two functions from $R^{+}$into $R^{+}$defined by

$$
f(x)= \begin{cases}x, & \text { if } x<1, \\ 1, & \text { if } x \geq 1, \quad g(x)=x(x+1)^{-1} .\end{cases}
$$

It is easy to see that $f(X)$ is closed, $f$ and $g$ are continuous, but they are not compatible (see [8, Example 2.5]).

(iii) Theorem 2 extends and improves also the corresponding results of [7, 8, 20-25].

As a consequence of Theorem 2 we have the following result:

COROLLARY 1. Let $T_{i}: X \rightarrow C B(X)(i=1,2, \ldots)$ and

$$
H\left(T_{i} x, T_{j} y\right) \leq \Phi\left(\max \left\{d(x, y), d\left(x, T_{i} x\right), d\left(y, T_{j} y\right), \frac{1}{2}\left(d\left(x, T_{j} y\right)+d\left(y, T_{i} x\right)\right)\right), \quad i \neq j\right.
$$

for all $x, y$ in $X$, where $\Phi: R^{+} \rightarrow R^{+}$is an increasing function satisfying conditions (1.1) and (1.2). Then the fixed point set $\left\{x: x \in T_{i} x\right\}, i=1,2, \ldots$ are nonempty and equal to each other. Moreover, if at least one of $\left\{T_{i}\right\}$ is continuous, then they are all closed.

PROOF. For the sake of convenience we prove the conclusions of Corollary only for the case of $i=1$ and $j=2$.

By Theorem 2, there exists an $z \in X$ such that $z \in T_{1} z \cap T_{2} z$.

Now we prove that the fixed point sets of $T_{1}$ and $T_{2}$ are equal to each other. In fact, if $u$ is a fixed point of $T_{1}$, i.e. $u \in T_{1} u$, then we have

$$
\begin{aligned}
d\left(u, T_{2} u\right) & \leq H\left(T_{1} u, T_{2} u\right) \\
& \leq \Phi\left(\max \left\{d(u, u), d\left(u, T_{1} u\right), d\left(u, T_{2} u\right), \frac{1}{2}\left(d\left(u, T_{2} u\right)+\left(d\left(u, T_{1} u\right)\right)\right\}\right)\right. \\
& \leq \Phi\left(\max \left\{0,0, d\left(u, T_{2} u\right), \frac{1}{2} d\left(u, T_{2} u\right)\right\}\right) \\
& \leq \Phi\left(d\left(u, T_{2} u\right)\right) .
\end{aligned}
$$

By Lemma 3 (iii), we have $d\left(u, T_{2} u\right)=0$. Since $T_{2} u$ is closed, $u \in T_{2} u$.

By the same way we can prove that if $w$ is a fixed point of $T_{2}$ then $w$ is also a fixed point of $T_{1}$. Hence we have $\left\{x \in X: x \in T_{1} x\right\}-\left\{x \in X: x \in T_{2} x\right\}$. 
Next, we prove that if $T_{1}$ (or $T_{2}$ ) is continuous, then the set of fixed points $\left\{x \in X: x \in T_{1} x\right\}$ is a closed set. In fact, let $\left\{x_{n}\right\} \subset\left\{x \in X: x \in T_{1} x\right\}$ and $x_{n} \rightarrow x$ as $n \rightarrow \infty$. Since $x_{n} \in T_{1} x_{n}$ and $T_{1} x_{n} \rightarrow T_{1} x$ as $n \rightarrow \infty$, we have

$$
\begin{aligned}
d\left(x, T_{1} x\right) & \leq d\left(x, x_{n}\right)+d\left(x_{n}, T_{1} x\right) \\
& \leq d\left(x, x_{n}\right)+H\left(T_{1} x_{n}, T_{1} x\right) \rightarrow 0 \text { as } n \rightarrow \infty,
\end{aligned}
$$

i.e. $d\left(x, T_{1} x\right)=0$. Therefore $x \in T_{1} x$.

This completes the proof.

REMARK 3. If all the mapping $T_{i}, i=1,2, \ldots$ in Corollary 1 are single-valued, then $T_{i}, i=1,2, \ldots$ have a unique common fixed point in $X$.

In fact, let $u, v \in X$ be two common fixed points of $T_{i}, i=1,2, \ldots$, then we have

$$
\begin{aligned}
d(u, v)- & d\left(T_{i} u, T_{j} v\right) \\
& \leq \Phi\left(\operatorname { m a x } \left\{d(u, v), d\left(u, T_{i} u\right), d\left(v, T_{j} v\right),\right.\right. \\
& \left.\left.\frac{1}{2}\left(d\left(u, T_{j} v\right)+d\left(v, T_{i} u\right)\right)\right\}\right) \\
& =\Phi(\max \{d(u, v), 0,0, d(u, v)\}) \\
& \leq \Phi(d(u, v)), \text { for all } i, j, i \neq j .
\end{aligned}
$$

Hence we have $d(u, v)=0$, i.e. $u=v$.

REMARK 4. The results of $[5$, Theorem 9], $[9,10,11,12,13$, Theorem 1], $[14$, Theorem $]$ and $[15$, Theorem 1, 3, 4] are all the special cases of Corollary.

DEFINITION. A function $\Psi\left(t_{1}, t_{2}, t_{3}, t_{4}, t_{5}\right): R^{+5} \rightarrow R^{+}$is called to satisfy the condition ( $\Psi$ ), if it is nondecreasing in each variable and there exists an increasing function $\Phi(t): R^{+} \rightarrow R^{+}$satisfying the conditions (1.1) and (1.2) such that

$$
\Psi(t, t, t, a t, b t) \leq \Phi(t), \quad \forall t \geq 0, a+b=3, a, b=1,2 .
$$

THEOREM 3. Let $F: X \rightarrow C C(X), S, T: X \rightarrow C B(X)$ be three multivalued mappings such that $S(X) \cup T(X) \subset F(X), F(X)$ is closed and satisfies the following conditions:

$$
H(S x, T y) \leq \Psi(d(F x, F y), d(F x, S x), d(F y, T y), d(F x, T y), d(F y, S x))
$$

for all $x, y$ in $X$, where $\Psi\left(t_{1}, t_{2}, t_{3}, t_{4}, t_{5}\right): R^{+5} \rightarrow R^{+}$satisfies condition ( $\left.\Psi\right)$. Then there exists a point $z \in X$ such that $F z \cap S z \cap T z \approx \varnothing$.

PROOF. Let

$$
t^{*}=\max \left\{d(F x, F y), d(F x, S x), d(F y, T y), \frac{1}{2}(d(F x, T y)+d(F y, S x))\right\} .
$$

Without loss of generality we can assume that $d(F x, T y) \geq d(F y, S x)$ (otherwise, it can be proved similarly). Then we have

$$
\begin{aligned}
t^{*} & \geq \max \{d(F x, F y), d(F x, S x), d(F y, T y)\}, \\
t^{*} & \geq \frac{1}{2}(d(F x, T y)+d(F y, S x)) \geq d(F y, S x) \\
2 t^{*} & \geq d(F x, T y)+d(F y, S x) \geq d(F x, T y)
\end{aligned}
$$


Using condition ( $\Psi)$ and (2.8) we have

$$
\begin{aligned}
H(S x, T y) & \leq \Psi\left(t^{*}, t^{*}, t^{*}, 2 t^{*}, t^{*}\right) \leq \Phi\left(t^{*}\right) \\
& =\Phi\left(\operatorname{Max}\left\{d(F x, F y), d(F x, S x), d(F y, T y), \frac{1}{2}(d(F x, T y)+d(F y, S x))\right\}\right) .
\end{aligned}
$$

Therefore, $F, S, T$ satisfies all conditions of Theorem 2. The conclusion of Theorem 3 follows from Theorem 2 immediately.

From Theorem 3 we can obtain the following

COROLLARY 2. Let $T_{i}: X \rightarrow C B(X), i=1,2, \ldots$ satisfy the following condition

$$
H(T x, T y) \leq \Psi\left(d(x, y), d\left(x, T_{i} x\right), d\left(y, T_{j} y\right), d\left(x, T_{j} y\right), d\left(y, T_{i} x\right)\right), \forall i, j, i \neq j
$$

for all $x, y$ in $X$, where $\Psi\left(t_{1}, b_{2}, t_{3}, t_{4}, t_{5}\right): R^{+5} \rightarrow R^{+}$satisfies condition ( $\Psi$ ). Then the fixed point sets $\left\{x \in X: x \in T_{i} x\right\}, i=1,2, \ldots$ are nonempty and equal to each other. Moreover, if one of $T_{i}, i=1,2, \ldots$ is continuous, then they are closed.

REMARK 5. Corollary 2 generalizes the corresponding result of [29].

\section{REFERENCES}

1. CHANG, S-S., Eixed Point Theorems and Applications, Chongqing Publishing House, Chongqing, 1984.

2. CHANG, S-S., On Common Fixed Point Theorem for a Family of $\Phi$-Contraction Mappings, Math Japonica, 29 (1984), 527-536.

3. CHANG, S-S., A Common Fixed Point Theorem for Commuting Mappings, Proc. Amer. Math. Soc. 83 (1981), 645-652.

4. CHANG, S-S. and GUO, W-P., Coincidence points and fixed points for 1-Set Contraction Mappings, J.Math. Research \& Exposition (to appear).

5. SASTRY, K. P. R., NAIDU, S. V. R. and PRASAD, J. R., Common Fixed Points for Multimaps in a Metric Space, Nonlinear Analo 13 (1989), 221-229.

6. KANEKO, H. and SESSAS., Fixed Point Theorems for Compatible multi-valued and single-valued mappings, Internat. J. Math. \& Math. Sci., 12 (1989), 257-262.

7. KANEKO, H. Single-valued and Multi-valued f-contractions, Boll. Un. Math. Ital, (6) 4-A (1985), 29-33.

8. JUNGCK, G., Common Fixed Point for Commuting and Compatible Maps on Compact, Proc. Amer. Math, 103 (1988), 977-983.

9. KUBIAK, T., Fixed Point Theorems for Contractive Type Mulitvalued Mappings, Math, Japonica, 30 (1985), 89-101.

10. SINGH, K. L. and WHITFIELD, J. H. M., Fixed Points of Contractive Type Multivalued Mappings, Math, Japonica, 27 (1982), 117-124.

11. ACHARI, J., Generalized Multi-valued Contractions and Fixed Points, Rev. Roum. Math. Pures Apple 24 (1979), 179-182.

12. ISÉKI, K., Multi-valued Contraction Mappings in Complete Metric Spaces, Rend.Sem. Mat. Univ. Padova, 53 (1975), 15-19.

13. KUBIACZYK, I., Some Fixed Point Theorems, Demonstratio Math, 6 (1976), 507-515.

14. KITA, T., A Common Fixed Point Theorem for Multivalued Mappings, Math. Japonica, 22 (1977), 113-116.

15. PAPAGEORGION, N. S., Fixed Point Theorems for Multifunctions in Metric and Vector Spaces, Nonlinear Anal. 7(1983), 763-770.

16. KHAN, M. S., Common Fixed Point Theorems for Multivalued Mappings, Pacific J. Math. 26 (1981), 337-347. 
17. KANG, S. M., CHO, C. L. and JUNGCK, G., Common Fixed Point of Compatible Mappings, Internat. J. Math. \& Math. Scie, 13 (1990), 61-66.

18. JUNGCK, G., Compatible Mappings and Common Fixed Points, Internat. J. Math \& Math. Sci., 2(1986), 771-779.

19. KANG, S. M. and RYU, J. W., A Common Fixed Point Theorem for Compatible Mappings, Math. Japonica, 35 (1990), 153-157.

20. JUNGCK, G., Commuting Mappings and Fixed Points, Amer. Math. Monthly, 83 (1976), 251-263.

21. DAS, K. M. and NAIK, K. V., Common Fixed Point Theorems for Commuting Maps on a Metric Space, Proc. Amer. Math. Soc., 77 (1979), 369-373.

22. CHATTERJI, H., A Note on Common Fixed Points and Sequences of Mappings, Bull. Calcutta Math. Soc. 72 (1980), 139-142.

23. JAISWAL, A. and SINGH, B., Fixed Point Theorems in Metric Space Over Topological Semifield, Math. Japonica, 21 (1976), 187-196.

24. MUKHERJEE, R. N., Common Fixed Points of Some Nonlinear Mappings, Indian J. Pure Appl. Math. 12 (1981), 930-933.

25. CIRIC, LJ. B., A Generalization of Banach's Contraction Principle, Proc. Amer. Math. Soc., 46 (1974), 267-273.

26. RHOADES, B. E., PARK, S. and MOON, K. B., On Generalizations of the Meir-Keeler Type Contraction Maps, L. Math. Anal. Apple, 148 (1990), 482-484.

27. JUNGCK, G., A Common Fixed Point Theorem for commuting Maps on $L$-spaces, Math. Japonica, 25 (1980), 81-85.

28. JUNGCK, G., Periodic and Fixed Points and Commuting Mappings, Proc. Amer. Math. Soc. 76 (1979), 333-339.

29. YEH, C. C., Some Fixed Point Theorems in Complete Metric Spaces, Math. Japonica, 23 (1978), 27-31. 


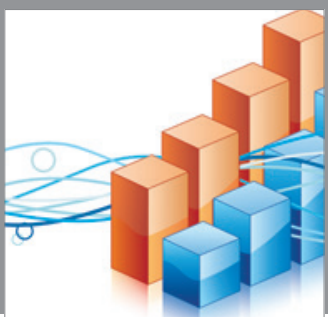

Advances in

Operations Research

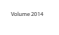

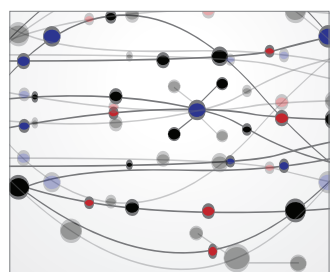

\section{The Scientific} World Journal
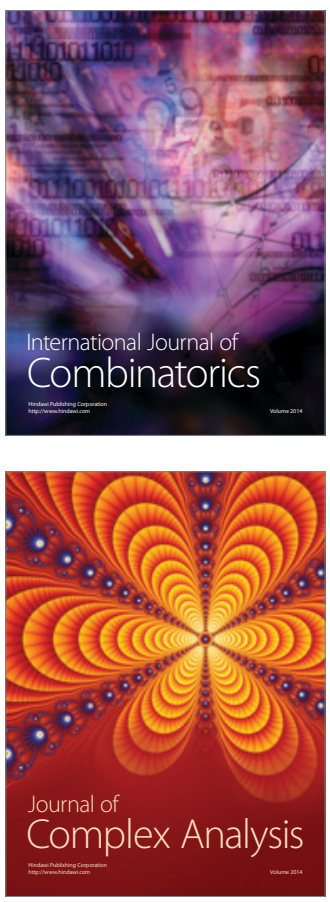

International Journal of

Mathematics and

Mathematical

Sciences
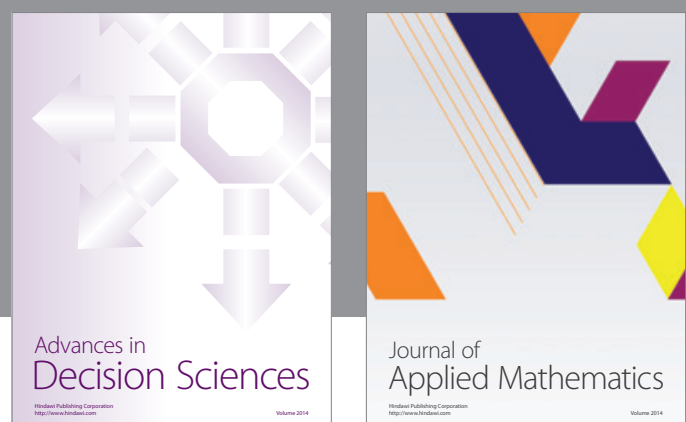

Journal of

Applied Mathematics
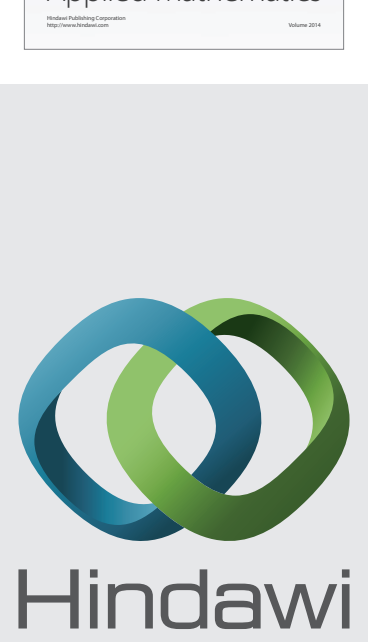

Submit your manuscripts at http://www.hindawi.com
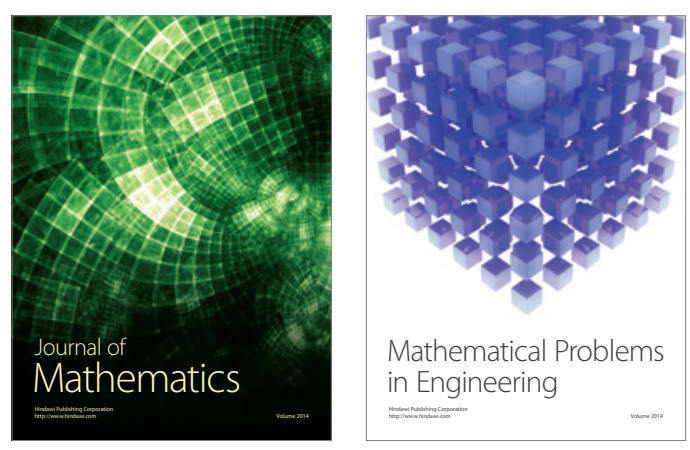

Mathematical Problems in Engineering
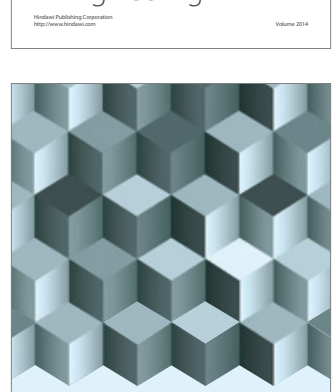

Journal of

Function Spaces
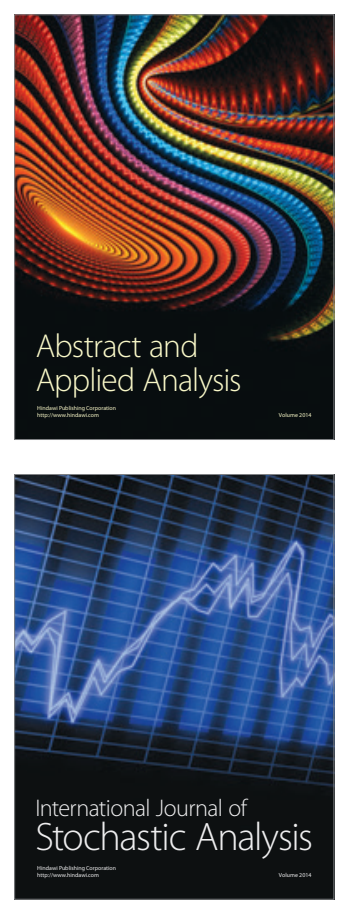

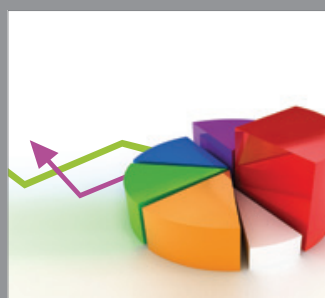

ournal of

Probability and Statistics

Promensencen
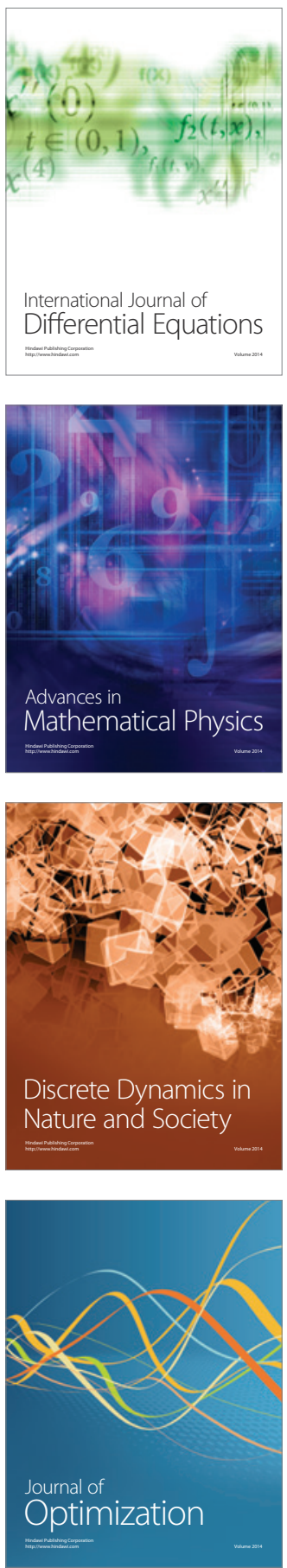